\title{
Conceptual Framework for Collaboratively Managing Coupled Human and Natural Systems under Climate Change Uncertainty
}

\author{
Tony Prato ${ }^{1}$ \\ ${ }^{1}$ University of Missouri, USA \\ Correspondence: Tony Prato, University of Missouri. Email: PratoA@missouri.edu
}

Received: December 5, 2015 Accepted: December 16, 2015 Online Published: December 22, 2015

doi:10.5539/enrr.v6n1p13

URL: http://dx.doi.org/10.5539/enrr.v6n1p13

\begin{abstract}
A collaborative decision making (CDM) framework is developed for managing coupled human and natural systems (CHANS) over time when managers are uncertain about one or more drivers of system behavior. The framework incorporates six elements: (1) framing the problem; (2) selecting management objectives; (3) choosing scenarios for future changes in one or more drivers of system behavior; (4) formulating alternative management actions; (5) estimating the values of management objectives and determining their compliance with maximum or minimum acceptable levels; and (6) determining preferred management actions for each driver scenario and time period. Application of the framework is illustrated for a hypothetical case study that determines preferred management actions over time for a highway corridor through a hypothetical national park based on four management objectives: minimizing soil erosion and vegetative losses along hiking trails in the highway corridor; and minimizing traffic congestion on the highway and visitor congestion on hiking trails in the highway corridor. Uncertainty about future visitor use of the highway corridor is taken into account by specifying low, medium, and high visitor use scenarios for the corridor. Preferred management actions for each visitor use scenario within time periods are determined using the fuzzy Technique for Order Preference by Similarity of Ideal Solution to rank management actions for each visitor use scenario. The preferred management action across visitor use scenarios for each time period is determined by applying the minimax regret criterion to maximum loss indices for the preferred management actions for visitor use scenarios.
\end{abstract}

Keywords: collaborative decision-making, managing coupled systems, uncertainty

\section{Introduction}

Collaborative decision making (CDM) is a process in which diverse stakeholders, such as federal, state, and local governmental agencies, communities, scientists, nongovernmental organizations, and private interests, participate in the decision-making process at a range of spatial and temporal scales (Wondolleck \& Yaffee, 2000). CDM has become an important form of decision-making in the management of coupled human and natural systems (CHANS) in the $21^{\text {st }}$ century (Johnson, 1999; Smith, McDonough, \& Mang 1999; Lybecker, Lamb, \& Ponds, 2002). CHANS are complex social-ecological systems for which natural and human elements interact (Liu et al., 2007). A primary motivation for CDM is the desire of CHANS' managers to assuage the "increasingly hostile, litigious, and seemingly paralyzed efforts to address issues related to natural resources management" (McDonald, 2001) and "overcome intractable conflicts in environmental planning and management" (Rutherford, Gibeau, Clark, \& Chamberlain, 2009).

CDM is a potentially viable alternative to the top-down scientific management or autocratic decision-making approaches to natural resource management that prevailed during the $20^{\text {th }}$ century. With autocratic decisionmaking, a single authority makes and implements management decisions. CDM and other integrative approaches to decision-making that acknowledge the social-ecological complexities and uncertainties inherent in the management of CHANS, such as adaptive governance or adaptive management (Holling, 1978; Walters, 1996; Parma, 1998; Prato, 2007), are appropriate in a democracy (Brunner et al., 2005). CHANS' managers for national forests, parks, and fish and wildlife refuges are required by law to involve the public in deciding how to manage those systems (Brown \& Harris, 2000). For example, the management plans developed for units managed by the U.S. National Park Service (NPS) must be "prepared by interdisciplinary teams including the park superintendent and staff, landscape architects, community planners, specialists in natural and cultural resources, environmental design specialists, concessions management specialists, interpretation experts, and 
professionals in other fields, as needed" (National Park Service, undated (a)). Such teams could be coincident to or part of a CDM group.

CDM can be viewed as "a transition from traditional top-down scientific management to a new form of adaptive governance" (Brunner et al., 2005) that is appropriate when local stakeholders want more involvement in decisions that affect their welfare and recognize the limitations, and in some cases failures, of scientific management (McLaughlin, Primm, \& Rutherford, 2005; Cherney \& Clark, 2009). On the downside, CDM can result in so-called "lowest common denominator" decisions that perpetuate existing power relationships (Pelletier, Kraak, McCullum, Uusitalo, \& Rich, 1999; Gunton \& Day, 2003; Peterson, Peterson, \& Peterson, 2005) and do not result in the best course of action (Rutherford, Gibeau, Clark, \& Chamberlain, 2009). The downside risks of CDM can be minimized by utilizing the best available knowledge from diverse sources "to produce outcomes that are rational, politically practical and morally justified, as well as acceptable to the decision makers themselves" (Rutherford et al., 2009).

CDM is not appropriate for all kinds of CHANS' management decisions. When management decisions need to be made in a relatively short period of time (e.g., deciding how to handle a wildfire on public land), there is not enough time and little to be gained by involving a wide range of stakeholders in developing a fire suppression and management plan. When time is of the essence in making management decisions, a more individual or autocratic decision-making approach is justified. In contrast, renovations made to a national park's visitor center do not have to be decided right away. It may be more appropriate to make renovation and similar decisions using a compromise-oriented, decision-making approach (Warner, 2015). In general, CDM is suitable for revising the management plans for a national park or forest, and deciding on major infrastructure improvements.

The U.S. Federal Advisory Committee Act (FCA) of 1972 is ambiguous regarding the extent to which federal agencies can incorporate CDM (as described here) into their decision-making processes (Long \& Beierle, 1999). If the CDM framework presented here is subject to the FCA, then the collaborative elements of the framework may have to be modified to ensure compliance with the requirements of the act.

Weinburg and Brandon (1999) identify six decision elements for successful implementation of CDM: (1) ensuring leadership and commitment; (2) framing the problem; (3) formulating alternatives and developing methods for evaluating alternatives; (4) collecting meaningful and reliable data; (5) selecting an alternative; and (6) developing a plan for implementing the selected alternative. The objective of this paper is to develop a conceptual framework for implementing a subset of the elements identified by Weinburg and Brandon (1999), namely elements two through five, referred to as targeted decision elements. This paper does not address the first and sixth elements listed above, or other factors that can influence the success of CDM. The latter include trust building, mutual recognition of interdependence, shared ownership of the process, clear mission, identification of common values, strategic plans, joint fact finding, and small wins (Ansell \& Gash, 2008).

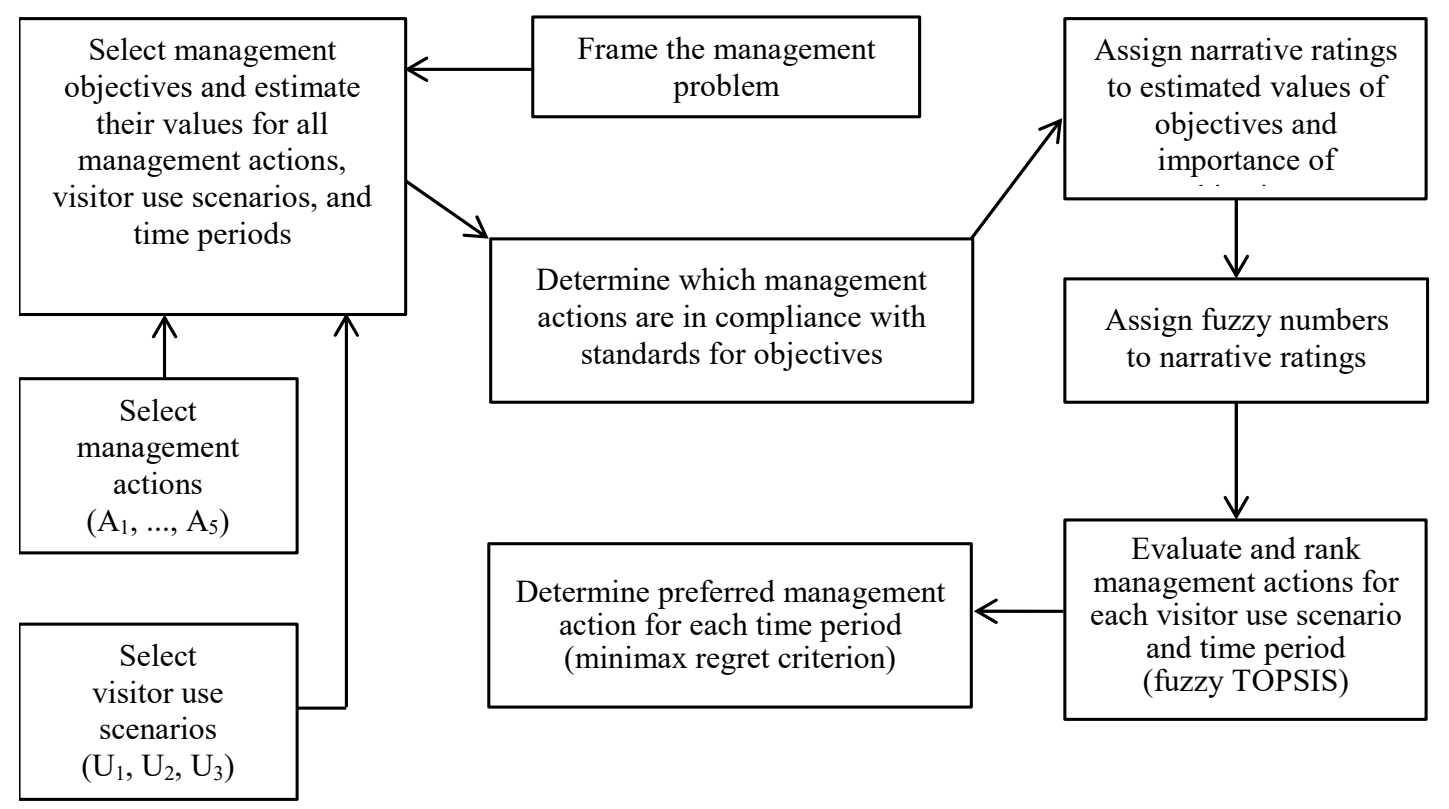

Figure 1. Major Elements of Conceptual Framework 


\section{Methods}

The conceptual framework described here accounts for uncertainty about the values of the drivers of behavior for a CHANS. Although the framework can be described in general terms, such an approach is too abstract and does not provide sufficient understanding to allow CHANS' mangers to apply the framework. For that reason, the conceptual framework is described in terms of a hypothetical case study that involves determining preferred management actions over time for a highway corridor through the hypothetical Cascadia National Park (CNP) in the United States. This section describes the assumptions and the six decision elements for the hypothetical case study (see Figure 1). The six decision elements are a restatement and expansion of the five targeted decision elements identified above.

\subsection{Assumptions for Hypothetical Case Study}

Because the preferred management action is determined in the same manner for all time periods, the hypothetical case study pertains to only one time period, namely the first time period. The example is based on the following assumptions.

1) The CNP's budget for evaluating, ranking, implementing, and monitoring management actions is $\$ 1$ million per time period;

2) Compliance of the estimated values of management objectives with their respective standards is evaluated based on the following reliability levels selected by the group: .90 for vegetative losses and traffic congestion on the highway; .85 for soil erosion on hiking trails; and .80 for congestion on hiking trails.

3) The group rates the estimated values of the objectives for each combination of management action and visitor use scenario, designated (A-U)), and the importance of the objectives using the narrative ratings listed in first column of Table 1. Each narrative rating is assigned the triangular fuzzy numbers listed in the second or third columns of Table 1.

4) Each interest represented in the group (e.g., governmental agency responsible for managing the park, private companies in gateway communities, scientists, nongovernmental organizations, etc.) is accorded equal importance in selecting the parameters listed in Table 2.

5) The group may not be able to reach agreement on some of the parameters listed in Table 2.

Table 1. Triangular fuzzy numbers for the narrative ratings of the estimated values and importance of management objectives

\begin{tabular}{lcc}
\hline Narrative rating & \multicolumn{2}{c}{ Triangular fuzzy $^{\text {numbers }}{ }^{\mathrm{a}}$} \\
\cline { 2 - 3 } & \multicolumn{1}{c}{ Values } & Importance $^{\text {Very low }}$ \\
Low & $(0.05,0.05,1)$ & $(0,0,1)$ \\
Moderate & $(0.05,1,3)$ & $(0,1,3)$ \\
High & $(3,5,7)$ & $(3,5,7)$ \\
Very high & $(7,9,10)$ & $(7,9,10)$ \\
\hline
\end{tabular}

a. Adapted from Chen (2000) and Prato (2012). The first number is the minimum value, the second number is the mode, and the third number is the maximum value for a triangular probability distribution.

Table 2. List of parameters ${ }^{\mathrm{a}}$

1. Number and length of time periods

2. Number and type of management actions

3. Objectives for evaluating and ranking management actions

4. Scenarios for future growth in visitor use of the corridor

5. Estimated values of objectives for management actions

6. Narrative ratings of the estimated values of the objectives and the importance of the objectives

7. Maximum acceptable levels of objectives

8. Reliability levels for compliance with maximum acceptable levels of objectives

9. Using fuzzy TOPSIS and the minimax regret criterion to evaluate and rank management actions 
a. The first parameter set includes parameters 1 through 4 and the second parameter set includes parameters 5 through 9.

Triangular fuzzy numbers are relatively easy to work with because the triangular probability distribution is a three-parameter distribution. Specifically, the triangular probability distribution is $T(a, b, c)=[2(x-a) /(c-a)(b-$ a)] for $\mathrm{a} \leq \mathrm{x} \leq \mathrm{b}$ and $\mathrm{T}(\mathrm{a}, \mathrm{b}, \mathrm{c})=[2(\mathrm{c}-\mathrm{x}) /(\mathrm{c}-\mathrm{a})(\mathrm{c}-\mathrm{b})]$ for $\mathrm{b}<\mathrm{x} \leq \mathrm{c}$, where $\mathrm{a}$ is the minimum value, $\mathrm{b}$ is the modal value, and $\mathrm{c}$ is the maximum value of $\mathrm{x}$ as illustrated in Figure 2. Other probability distributions can be used to assign fuzzy numbers to the narrative ratings.

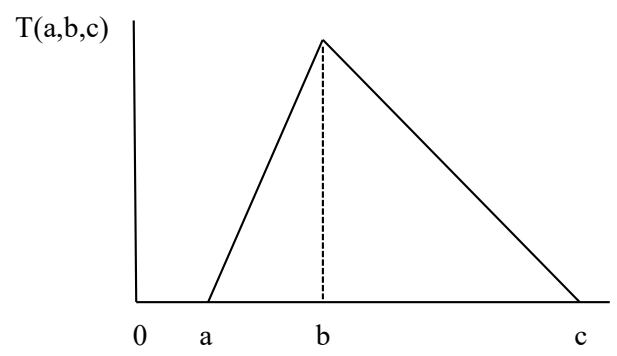

Figure 2. Triangular Probability Distribution

It would be burdensome for the group to narratively rate each and every estimated value of an objective, especially if there are multiple objectives and time periods as is the case for the empirical example. The burden of rating can be substantially reduced by asking the group to create an assignment algorithm that determines the narrative ratings assigned to different ranges of the estimated values of the objectives. An example of an assignment algorithm for objective $y$ : the estimated value of $y$, designated $\hat{y}$, is 'very low' if $0 \leq \hat{y} \leq y_{1}$, 'low' if $y_{1}<\hat{y} \leq y_{2}$, 'moderate' if $\mathrm{y}_{2}<\hat{\mathrm{y}} \leq \mathrm{y}_{3}$, 'high' if $\mathrm{y}_{3}<\hat{\mathrm{y}} \leq \mathrm{y}_{4}$, and 'very high' if $\mathrm{y}_{4}<\hat{\mathrm{y}} \leq \mathrm{y}_{5}$, where zero is the minimum estimated value and $\mathrm{y}_{5}$ is the maximum estimated value of $\mathrm{y}$ across all $(\mathrm{A}-\mathrm{U})_{\mathrm{i}} \mathrm{s}$ and time periods.

If members of the group disagree about the values of one or more of the parameters listed in Table 2 and those disagreements cannot be resolved, particularly disagreements about parameters 1 through 4 (i.e., first parameter set), then it may not be possible to obtain comparable results using the framework described here. For example, suppose one sub-group of members wants to evaluate and rank only management actions $A_{1}, A_{2}$, and $A_{3}$ and another sub-group of members wants to evaluate and rank only management actions $A_{3}, A_{4}$, and $A_{5}$. In this case, separate rankings of the management actions for each sub-group would be of little value in determining the preferred management action for the group as a whole because only $\mathrm{A}_{3}$ is common to both sets of management actions. Disagreements among group members about parameters 5 through 9 (i.e., second parameter set) can be handled as follows. Suppose the two sub-groups agree on all of the assumptions listed above except the narrative ratings of the importance of the four objectives. The management actions are ranked using the narrative ratings for each sub-group. If the preferred management actions for the two sub-groups are the same, then there is not a problem. If the preferred management actions for the two sub-groups are different, then it would be necessary to resolve the differences in the narrative ratings and redo the ranking of management actions.

\subsection{Framing the Problem}

Managing the highway corridor poses a major challenge (or problem) for CNP. Increases in visitor use of the corridor during the past 10 years have had negative impacts on the corridor's soil and vegetation. In addition, visitors have complained about traffic congestion on the highway and congestion on hiking trails in the corridor. Future increases in park visitation are expected to exacerbate negative impacts on natural resources and visitor satisfaction. Park managers and other stakeholders believe negative impacts of visitation can be alleviated by implementing management actions that alter the extent and/or nature of visitor use in the corridor. The corridor is the most visited area of the park, making it an important source of visitor satisfaction and income and employment in the park's gateway communities.

A collaborative group (group for short) has been created consisting of park managers, scientists, nongovernmental environmental organizations, and businessman from gateway communities for CNP. The group has agreed to use CDM and supporting analytical methods to determine preferred corridor management actions for each of four, five-year time periods that cover a 20-year planning period. A major advantage of determining a preferred management action for each time period is that it allows the group to ascertain whether or not it is advantageous to adapt corridor management actions over time periods (Prato \& Paveglio, 2014). 


\subsection{Selecting Management Objectives}

Since CNP is a national park located in the U.S., management objectives for the highway corridor need to be selected based on the mission of the U.S. National Park Service which is “... to conserve the scenery and natural and historic objects and the wildlife therein and to provide for the enjoyment of the same by such manner and by such means as will leave them unimpaired for the enjoyment of future generation" (National Park Service Organic Act of 1914).

The group decides to evaluate management actions for the highway corridor based on four objectives: minimizing soil erosion and vegetative losses along hiking trails in the highway corridor, which supports the mission of conserving "the scenery and natural and historic objects and the wildlife therein;" and minimizing traffic congestion on the highway and visitor congestion on hiking trails in the corridor, which supports the mission of providing "for the enjoyment of the same."

\subsection{Choosing Scenarios for Future Visitor Use in the Corridor}

Because the group is uncertain about future visitor use in the corridor, management actions are evaluated and ranked for three future visitor use scenarios for the corridor, namely, low $\left(U_{1}\right)$, medium $\left(U_{2}\right)$, and high $\left(U_{3}\right)$ use. Although the number of visitor use scenarios is arbitrary, the principles of alternative futures analysis (Steinitz et al., 2003) indicate that visitor use scenarios should be substantially different from one another. The group uses the Delphi method to select the visitor use scenarios (see section 2.6 for more details).

\subsection{Formulating Alternative Management Actions}

In order to determine the preferred management actions for CNP's highway corridor, it is necessary for the group to formulate alternative management actions for the corridor. Although there is no single way to do this, the management actions selected for evaluation should be sufficiently different from one another, capable of achieving the management objectives established for the corridor, and financially feasible. If management actions are too similar, it may be not be possible to identify unequivocally superior preferred management actions for time periods If the management actions are incapable of achieving the management objectives established for the corridor, those actions would be incompatible with the mission of NPS outlined above. Finally, management actions must be financially feasible meaning the costs of each management action cannot exceed the budget available for planning and implementing the preferred management action.

Based on public comments and other information, the group identifies five management actions for the highway corridor, as follows:

- $\mathrm{A}_{1}$ : no change in the management of transportation and hiking in the highway corridor.

- $\mathrm{A}_{2}$ : encourage visitors to use hiking trails other than those in the corridor by giving them maps that show the location of less congested hiking trails in the park and providing free bus transportation in the corridor during the peak visitor season.

- $\quad \mathrm{A}_{3}$ : initiate a permit system that limits the number of personal motor vehicles allowed on the highway and provide free bus transportation in the corridor during the peak visitor season.

- $\quad \mathrm{A}_{4}$ : charge a higher entrance fee for park visitors that travel the highway in their personal motor vehicles and/or hike the most popular trails in the corridor during the peak visitor season, and provide free bus transportation in the corridor during the peak visitor season.

- $\mathrm{A}_{5}$ : disallow the use of personal vehicles on the highway and provide free bus transportation in the corridor during the peak visitor season, and temporarily close the most crowded hiking trails in the corridor when the number of hikers on those trails reaches carrying capacity.

In practice, the parameters for each management action would need to be spelled out in detail before the actions can be evaluated. These parameters include: (1) number of buses, the frequency of bus service, and the location of bus stops for $\mathrm{A}_{2}$ through $\mathrm{A}_{5}$; (2) limits on the number of personal motor vehicles allowed on the highway and the number of visitors permitted on the most popular hiking trails in the corridor during the peak visitor season for $\mathrm{A}_{3}$; (3) additional entrance fee that park visitors would be charged for traveling the highway in their personal motor vehicles and/or hiking the most crowded trails in the corridor during the peak visitor season for $\mathrm{A}_{4}$; and (4) number of hikers allowed on each hiking trail in the corridor before the trail is temporarily closed for $\mathrm{A}_{5}$.

\subsection{Estimating Values of Objectives and Determining Compliance of Objectives with Standards}

The proposed framework requires estimating the values of management objectives for all $(\mathrm{A}-\mathrm{U})_{\mathrm{i}} \mathrm{s}$ and time periods and determining which management actions are in compliance with the standards established for the objectives. 
Compliance is evaluated two ways. First, the values of objectives for management actions that have already been implemented in CNP are estimated using monitoring data for those actions. For example, monitoring data can be used to estimate the values of the objectives for $A_{1}$. Second, the values of the objectives for management actions that have not been implemented are estimated using expert judgment (e.g., the Delphi method), surveys, and/or simulation models.

The Delphi method (Linstone \& Turoff, 2002) uses a questionnaire containing information and opinion feedback to query a panel of experts regarding their forecasts of a future event, such as the values of the objectives under $\mathrm{A}_{2}$ through $\mathrm{A}_{5}$ for each visitor use scenario and time period. The Delphi method progresses in rounds in which panel members answer questions, and a facilitator anonymously summarizes the values of the objectives from the previous round as well as the reasons panel members gave for choosing those values. Panel members are allowed to revise the values of the objectives they gave in the previous round based on the information provided by the facilitator. The process continues for a predetermined number of rounds. The final values of the objectives are equated to the mean or median of the values panel members submitted in the last round.

The Delphi method can be used to estimate hiking intensities on trails in the highway corridor for different $(\mathrm{A}-\mathrm{U})_{\mathrm{i}}$ scenarios. Then, the effects of estimated hiking intensities on vegetation under each management action can be estimated using standardized experimental procedures (Cole \& Bayfield, 1993; Hill \& Pickering, 2009; Pickering, Hill, Newsome, \& Leung, 2010), and on soil erosion using the Variable Cross-Sectional Area method (Olive \& Marion, 2009). Surveys of park visitors can be used to estimate unacceptable levels of traffic congestion on the highway and visitor congestion on hiking trails. The Delphi method can be used along with surveys of highway users to specify unacceptable levels of traffic congestion on the highway and visitor congestion on hiking trails.

Compliance of management actions with the standards for objectives is evaluated by determining whether the estimated value(s) of the objectives for each $(\mathrm{A}-\mathrm{U})_{\mathrm{i}}$ exceeds the maximum acceptable levels of vegetative losses $\left(\mathrm{VL}_{\max }\right)$, soil erosion along hiking trails $\left(\mathrm{SE}_{\max }\right)$, traffic congestion on the highway $\left(\mathrm{CH}_{\max }\right)$, and visitor congestion on hiking trails $\left(\mathrm{CT}_{\max }\right)$ in the corridor. If there are multiple estimated values of the objectives, then compliance with the standards for objectives is evaluated as follows. First, several probability distributions are fitted to the multiple estimated values of the objective for each $(\mathrm{A}-\mathrm{U})_{\mathrm{i}}$. Second, the best fitting probability distribution is determined for each objective and $(\mathrm{A}-\mathrm{U})_{\mathrm{i}}$. Third, the best fitting probability distribution for each objective and (A$\mathrm{U})_{\mathrm{i}}$ is used to determine whether or not the estimated values of the objective for each $(\mathrm{A}-\mathrm{U})_{\mathrm{i}}$ are in compliance with the corresponding standard for that objective. The first two steps can be performed using Simetar (Richardson, Schumann, \& Feldman 2008; Prato et al., 2010).

The third step is illustrated for vegetative losses and visitor congestion on hiking trails. A management action is in compliance with the standards for vegetative losses and congestion on hiking trails if and only if $\operatorname{Pr}\left\{\mathrm{VL} \leq \mathrm{VL}_{\max }\right\}$ $\geq 1-\alpha$ and $\operatorname{Pr}\left\{\mathrm{CT} \leq \mathrm{CT}_{\max }\right\} \geq 1-\beta$, where probabilities are calculated using the best fitting probability distributions for the estimated values of VL and CT, $1-\alpha$ is the reliability level for compliance with the standard for vegetative losses, and $1-\beta$ is the reliability level for compliance with the standard for visitor congestion on hiking trails. $\mathrm{VL}_{\max }, \mathrm{CT}_{\max }, \alpha$, and $\beta$ are chosen by the group. For example, if the group determines that exceeding the maximum acceptable level of vegetative losses is a more serious than exceeding the maximum acceptable level of visitor congestion on hiking trails, then $\alpha$ would be less than $\beta$, which implies $1-\alpha>1-\beta$.

\subsection{Ranking Management Actions and Determine Preferred Management Actions}

A multiple-objective, decision-making method is used to rank management actions. Several multiple-objective, decision-making methods are available for this purpose (Herath \& Prato, 2006). The hypothetical case study evaluates and ranks the five management actions for each time period using a two-step procedure described below.

\subsubsection{First step - Applying Fuzzy TOPSIS}

The fuzzy Technique for Order Preference by Similarity of Ideal Solution (fuzzy TOPSIS) (Chen 2000) is a fuzzy, multiple-objective, decision-making method that ranks alternative management actions based on how close (or how far away) the estimated values of the objectives for those management actions are to the most (or least) desirable values of positive (or negative) objectives (Chen \& Hwang, 1992; Prato, 2009, 2012). Fuzzy TOPSIS has three advantages relative to other multiple-objective, decision-making methods. First, it requires decision-makers to state their preferences for the estimated values and importance of management objectives using linguistic variables or narrative ratings, which is relatively easy to do. Second, fuzzy TOPSIS does not assume utility independence of objectives as do multiple-objective, decision-making methods based on an additive utility function. Utility independence implies that the marginal utility of one objective is independent of the amounts of all other objectives. Third, unlike the use of an additive utility function, fuzzy TOPSIS does not assume the decision-maker is risk neutral. A risk-neutral decision-maker ranks decision alternatives based solely on the 
expected values of the objectives for alternatives (i.e., variation around the expected value does not affect the ranking).

Applying fuzzy TOPSIS to the hypothetical case study involves three steps, as follows:

1) The group uses linguistic variables to rate both the estimated values of the objectives for each visitor use scenario and time period and the importance of objectives.

2) Fuzzy numbers are assigned to linguistic variables.

3) Management actions are ranked for each visitor use scenario and time period. The preferred management action for each visitor use scenario and time period is the top-ranked management action for that scenario and time period.

\subsubsection{Second Step - Applying Minimax Regret Criterion}

The preferred management action for each time period is determined by applying the minimax regret criterion to the preferred management actions for the three visitor use scenarios for that time period. The minimax regret criterion chooses as the preferred management action the one that minimizes a maximum loss index (MLI) for the preferred management actions for the three visitor use scenarios. An empirical example of applying fuzzy TOPSIS and the minimax regret criterion to the hypothetical case study is given in sections 3.2 and 3.3, respectively.

\section{Results}

This section presents the results for the hypothetical case study.

\subsection{Compliance Evaluation and Narrative Ratings}

Table 3 summarizes the outcomes of applying the probabilistic decision rules for determining compliance of management actions with the standards for management objectives for visitor use scenario $U_{2}$ in the first time period. Table 4 shows that $A_{1}$ is not in compliance and $A_{2}$ through $A_{5}$ are in compliance with the standards for management objectives. $A_{1}$ is not in compliance because it violates the standards for trail congestion and vegetative losses. This result would justify excluding $A_{1}$ from further consideration. However, since the U.S. National Environmental Policy Act of 1970 requires federal agencies to evaluate the no action alternative in their environmental impact assessment, $A_{1}$ is retained in the ranking of management actions.

The group's narrative ratings of the estimated values of the objectives for the five management actions and the importance of objectives, and the corresponding triangular fuzzy numbers based on Table 1 are listed in Table 4.

Table 3. Probabilistic decision rules for determining compliance of management actions with minimum and maximum acceptable values of the objectives for five management actions under visitor use scenario $\mathrm{U}_{2}$, first time period

\begin{tabular}{|c|c|c|c|c|c|c|}
\hline Action & $\begin{array}{l}\text { Estimated } \\
\text { net } \operatorname{cost}^{\mathrm{a}}\end{array}$ & $\begin{array}{l}\text { Traffic congestion } \\
(\mathrm{CH})^{\mathrm{b}}\end{array}$ & $\begin{array}{l}\text { Trail congestion } \\
(\mathrm{CT})^{\mathrm{c}}\end{array}$ & $\begin{array}{l}\text { Soil erosion } \\
(\mathrm{SE})^{\mathrm{d}}\end{array}$ & $\begin{array}{l}\text { Vegetative losses } \\
(\mathrm{VL})^{\mathrm{b}}\end{array}$ & $\begin{array}{l}\text { Is management action in } \\
\text { compliance with standards? }\end{array}$ \\
\hline $\mathrm{A}_{1}$ & .2 & $\operatorname{Pr}\left(\mathrm{CH} \leq \mathrm{CH}_{\max }\right)=.92$ & $\mathrm{PV}\left(\mathrm{CT} \leq \mathrm{CT}_{\max }\right)=.75^{\mathrm{e}}$ & $\operatorname{Pr}\left(\mathrm{SE} \leq \mathrm{SE}_{\max }\right)=.86$ & $\operatorname{Pr}\left(\mathrm{VL} \leq \mathrm{VL}_{\max }\right)=.85^{\mathrm{e}}$ & No \\
\hline $\mathrm{A}_{2}$ & .6 & $\operatorname{Pr}\left(\mathrm{CH} \leq \mathrm{CH}_{\max }\right)=.94$ & $\mathrm{PV}\left(\mathrm{CT} \leq \mathrm{CT}_{\max }\right)=.85$ & $\operatorname{Pr}\left(\mathrm{SE} \leq \mathrm{SE}_{\max }\right)=.90$ & $\operatorname{Pr}\left(\mathrm{VL} \leq \mathrm{VL}_{\max }\right)=.91$ & Yes \\
\hline $\mathrm{A}_{3}$ & .8 & $\operatorname{Pr}\left(\mathrm{CH} \leq \mathrm{CH}_{\max }\right)=.95$ & $\mathrm{PV}\left(\mathrm{CT} \leq \mathrm{CT}_{\max }\right)=.82$ & $\operatorname{Pr}\left(\mathrm{SE} \leq \mathrm{SE}_{\max }\right)=.85$ & $\operatorname{Pr}\left(\mathrm{VL} \leq \mathrm{VL}_{\max }\right)=.92$ & Yes \\
\hline $\mathrm{A}_{4}$ & .5 & $\operatorname{Pr}\left(\mathrm{CH} \leq \mathrm{CH}_{\max }\right)=.91$ & $\mathrm{PV}\left(\mathrm{CT} \leq \mathrm{CT}_{\max }\right)=.82$ & $\operatorname{Pr}\left(\mathrm{SE} \leq \mathrm{SE}_{\max }\right)=.87$ & $\operatorname{Pr}\left(V L \leq V L_{\max }\right)=.94$ & Yes \\
\hline $\mathrm{A}_{5}$ & .7 & $\operatorname{Pr}\left(\mathrm{CH} \leq \mathrm{CH}_{\max }\right)=.95$ & $\mathrm{PV}\left(\mathrm{CT} \leq \mathrm{CT}_{\max }\right)=.80$ & $\operatorname{Pr}\left(\mathrm{SE} \leq \mathrm{SE}_{\max }\right)=.86$ & $\operatorname{Pr}\left(V L \leq V L_{\max }\right)=.95$ & Yes \\
\hline
\end{tabular}

a. Cost minus revenues generated in millions of dollars.

b. Reliability level is .90 .

c. Reliability level is .80 .

d. Reliability level is .85 .

e. Compliance standards for objectives are violated

\subsection{Determining Preferred Management Action for Visitor Use Scenarios}

At the beginning of each time period, fuzzy TOPSIS is applied to: (1) $A_{1}$ and $U_{1}, A_{2}$ and $U_{1}, A_{3}$ and $U_{1}, A_{4}$ and $U_{1}$, and $A_{5}$ and $U_{1}$ to determine the preferred management action under $U_{1}$; (2) $A_{1}$ and $U_{2}, A_{2}$ and $U_{2}, A_{3}$ and $U_{2}, A_{4}$ 
and $U_{2}$, and $A_{5}$ and $U_{2}$ to determine the preferred management action under $U_{2}$; and (3) $A_{1}$ and $U_{3}, A_{2}$ and $U_{3}, A_{3}$ and $U_{3}, A_{4}$ and $U_{3}$, and $A_{5}$ and $U_{3}$ to determine the preferred management action under $U_{3}$.

The following steps illustrate how fuzzy TOPSIS is used to determine the preferred management action under $\mathrm{U}_{2}$ for one time period. The first step is to determine which objectives are positive and which are negative. A positive objective is one for which more of the objective is desirable and a negative objective is one for which less of the objective is desirable. The four objectives for the hypothetical case study are negative because less is preferred to more of the objectives. Therefore, the management actions are ranked based on minimizing the four objectives. The triangular fuzzy positive- and negative-ideal solutions for the four objectives are $\mathrm{v}_{\mathrm{j}}^{+}=(0,0,0)$ and $\mathrm{v}_{\mathrm{j}}^{-}=(1,1,1)$.

The second step is to calculate the distances of the triangular fuzzy numbers assigned to the linguistic ratings of the estimated values of the management objectives for each $(\mathrm{A}-\mathrm{U})_{\mathrm{i}}$ given in Table 4 from the fuzzy positive-ideal solution $\left(\mathrm{d}_{\mathrm{i}}^{+}\right)$and fuzzy negative-ideal solution $\left(\mathrm{d}_{\mathrm{i}}^{-}\right)$, and the closeness coefficient $\left(\mathrm{E}_{\mathrm{i}}\right)$. The procedures for the second step are described for $(\mathrm{A}-\mathrm{U})_{\mathrm{i}} \mathrm{s}$ involving $\mathrm{U}_{2}$ followed by an empirical example.

$\mathrm{d}_{\mathrm{i}}^{+}, \mathrm{d}_{\mathrm{i}}^{-}$, and $\mathrm{E}_{\mathrm{i}}$ are defined as follows:

$$
\begin{gathered}
\mathrm{d}_{\mathrm{i}}^{+}=\sum_{\mathrm{j}} \mathrm{d}\left(\mathrm{w}_{\mathrm{j}} \mathrm{r}_{\mathrm{ij}}, \mathrm{v}_{\mathrm{j}}^{+}\right) \\
\mathrm{d}_{\mathrm{i}}^{-}=\sum_{\mathrm{j}} \mathrm{d}\left(\mathrm{w}_{\mathrm{j}} \mathrm{r}_{\mathrm{ij}}, \mathrm{v}_{\mathrm{j}}^{-}\right) \\
\mathrm{E}_{\mathrm{i}}=\mathrm{d}_{\mathrm{i}}^{+} /\left(\mathrm{d}_{\mathrm{i}}^{+}+\mathrm{d}_{\mathrm{i}}^{-}\right) \quad\left(0 \leq \mathrm{E}_{\mathrm{i}} \leq 1\right)
\end{gathered}
$$

where:

$\mathrm{i}=\mathrm{A}_{1}$ and $\mathrm{U}_{2}, \mathrm{~A}_{2}$ and $\mathrm{U}_{2}, \mathrm{~A}_{3}$ and $\mathrm{U}_{2}, \mathrm{~A}_{4}$ and $\mathrm{U}_{2}$, and $\mathrm{A}_{5}$ and $\mathrm{U}_{2}$;

$\mathrm{j}=\mathrm{CT}, \mathrm{CH}, \mathrm{SE}$, and VL;

$\mathrm{W}_{\mathrm{j}}=$ normalized triangular fuzzy number for the group's narrative rating of the importance of objective $\mathrm{j}$;

$\mathrm{r}_{\mathrm{ij}}=$ normalized triangular fuzzy number for the group's narrative rating of the estimated effect of $(\mathrm{A}-\mathrm{U})_{\mathrm{i}}$ on objective $\mathrm{j}$;

$\mathrm{d}\left(\mathrm{w}_{\mathrm{j}} \mathrm{r}_{\mathrm{ij}}, \mathrm{v}_{\mathrm{j}}^{+}\right)=$vertex distance between the weighted normalized fuzzy effect of $(\mathrm{A}-\mathrm{U})_{\mathrm{i}}$ on objective $\mathrm{j}$ and the positive-ideal solution for objective $\mathrm{j}$; and

$\mathrm{d}\left(\mathrm{w}_{\mathrm{j}} \mathrm{r}_{\mathrm{ij}}, \mathrm{v}_{\mathrm{j}}^{-}\right)=$vertex distance between the weighted normalized fuzzy effect of $(\mathrm{A}-\mathrm{U})_{\mathrm{i}}$ on objective $\mathrm{j}$ and the negative-ideal solution for attribute $\mathrm{j}$.

The vertex distance between two triangular fuzzy numbers $\mathrm{z}_{1}=\left(\mathrm{e}_{1}, \mathrm{e}_{2}, \mathrm{e}_{3}\right)$ and $\mathrm{z}_{2}=\left(\mathrm{k}_{1}, \mathrm{k}_{2}, \mathrm{k}_{3}\right)$ is $\mathrm{d}\left(\mathrm{z}_{1}, \mathrm{z}_{2}\right)=$ $\left\{0.33\left[\left(\mathrm{e}_{1}-\mathrm{k}_{1}\right)^{2}+\left(\mathrm{e}_{2}-\mathrm{k}_{2}\right)^{2}+\left(\mathrm{e}_{3}-\mathrm{k}_{3}\right)^{2}\right]\right\}^{0.5}$, where $\mathrm{z}_{1}=\mathrm{w}_{\mathrm{j}} \mathrm{r}_{\mathrm{ij}}$ and $\mathrm{z}_{2}=\mathrm{v}_{\mathrm{j}}^{+}$or $\mathrm{v}_{\mathrm{j}}^{-}$in equations (1) and (2).

As $\mathrm{E}_{\mathrm{i}}$ approaches 0 (or 1$),(\mathrm{A}-\mathrm{U})_{\mathrm{i}}$ moves farther away from (or closer to) the positive-ideal solution and closer to (or farther away from) the negative-ideal solution. Because the desirability of $(\mathrm{A}-\mathrm{U})_{\mathrm{i}}$ increases (or decreases) as the closeness coefficient for $(\mathrm{A}-\mathrm{U})_{\mathrm{i}}$ approaches one (or zero), the higher (or lower) the closeness coefficient the more preferred (or less preferred) is $(A-U)_{i}$. Therefore, the $(A-U)_{i}$ s are ranked in descending order of their closeness coefficients (i.e., the lower the closeness coefficient, the lower the rank). Since $\mathrm{U}_{2}$ is common to all five $(\mathrm{A}-\mathrm{U})_{\mathrm{i}} \mathrm{s}$, the rank order for the five $(\mathrm{A}-\mathrm{U})_{\mathrm{i}} \mathrm{s}$ implies a rank order for the five management actions. For example, if the rank order of $(A-U)_{i} S$ is $A_{3}$ and $U_{2}$ is preferred to $A_{2}$ and $U_{2}$ is preferred to $A_{4}$ and $U_{2}$ is preferred to $A_{5}$ and $U_{2}$ is preferred to $A_{1}$ and $U_{2}$, then the rank order of management actions under $U_{2}$ is $A_{3}$ is preferred to $A_{2}$ is preferred to $A_{4}$ is preferred to $A_{5}$ is preferred to $A_{1}$. Therefore, $A_{3}$ is the preferred management action under $U_{2}$ in the first time period. This ranking procedure is repeated for $(A-U)_{i} S$ involving $U_{1}$ and $U_{3}$ to determine the preferred management actions under those visitor use scenarios in the first time period.

The following empirical example illustrates how fuzzy TOPSIS is used to determine the preferred management actions for sub-groups I and II under visitor use scenario $U_{2}$ in the first time period based on Table 4. Similar procedures are used to determine the preferred management actions for visitor use scenarios $U_{1}$ and $U_{3}$ in the first time period and visitor use scenarios $\mathrm{U}_{1}, \mathrm{U}_{2}$, and $\mathrm{U}_{3}$ in the second through fourth time periods.

Calculating the normalized fuzzy effect (i.e., values of $r_{i j}$ in equations (1) and (2)) of (A-U) $)_{i}$ on each objective involves three steps. The first step is to calculate the normalized fuzzy effects matrices, which show the fuzzy effects of the $12(\mathrm{~A}-\mathrm{U})_{\mathrm{i}} \mathrm{s}$ on the four management objectives. The $\mathrm{i}-\mathrm{j}$ th element of the normalized fuzzy effects matrix is: 


$$
r_{i j}=\left(a_{j}^{-} / c_{i j}, a_{j}^{-} / b_{i j}, a_{j}^{-} / a_{i j},\right) \text { where } a_{j}^{-}=\min _{i} a_{i j}(j=P C, S E, T C)
$$

The normalized fuzzy effects matrix under visitor use scenario $\mathrm{U}_{2}$ in the first time period is given in Table 5 .

The second step is to calculate weighted normalized fuzzy effects matrices for sub-groups I and II as shown in Table 6. The weighted normalized fuzzy effect of $\mathrm{A}_{1}-\mathrm{U}_{2}$ on $\mathrm{CT}$ equals $\mathrm{w}^{\mathrm{I}} \mathrm{CT}^{*} \mathrm{r}_{\mathrm{A} 1-\mathrm{U} 2, \mathrm{CT}}=$ $\left(.3^{*} .005, .5 * .005, .7 * .00556\right)=(.0015,0025, .00389)$ for subgroup I and $\mathrm{w}^{\mathrm{II}} \mathrm{CT}^{*} \mathrm{r}_{\mathrm{A} 1-\mathrm{U} 2, \mathrm{CT}}=\left(.7^{*} .0035, .9^{*} .0045\right.$ $1.0 * .00556)=(.0035, .0045, .00556)$ for subgroup II, where $\mathrm{w}_{\mathrm{CT}}^{\mathrm{I}}$ is the normalized triangular fuzzy number for the importance of CT for sub-group $\mathrm{I}, \mathrm{w}^{\mathrm{II}} \mathrm{CT}$ is the normalized triangular fuzzy number for the importance of CT for sub-group II, and $r_{\mathrm{A} 1-\mathrm{U} 2, \mathrm{CT}}$ is the normalized triangular fuzzy effect of $\mathrm{A}_{1}-\mathrm{U}_{2}$ on $\mathrm{CT}$.

Distances of management actions from the positive- and negative-ideal solutions, vertex distances, closeness coefficients, and ranks of management actions for sub-groups I and II are given in Table 7. The vertex distances imply the following ranking of management actions under $U_{2}$ in the first time period for both sub-groups: $A_{5}$ is preferred to $A_{3}$ is preferred to $A_{4}$ is preferred to $A_{2}$ is preferred to $A_{1}$. Therefore, $A_{5}$ is the preferred management action under $U_{2}$ in the first time period for both subgroups. The same procedure is used to determine the preferred management actions for visitor use scenarios $U_{1}$ and $U_{3}$ in the first time period and for visitor use scenarios $U_{1}, U_{2}$, and $\mathrm{U}_{3}$ in the second through fourth time periods. Suppose the preferred management action for the first time period is $A_{4}$ under $U_{1}$ and $A_{5}$ under $U_{3}$.

Table 4. Narrative ratings of the estimated values of the objectives for management actions for visitor use scenario $\mathrm{U}_{2}$ in the first time period and the importance of the objectives, and corresponding triangular fuzzy numbers

\begin{tabular}{ccccc}
\hline Management action & $\mathrm{CT}^{\mathrm{a}}$ & $\mathrm{CH}^{\mathrm{b}}$ & $\mathrm{SE}^{\mathrm{c}}$ & $\mathrm{VL}^{\mathrm{d}}$ \\
\hline $\mathrm{A}_{1}$ & Very high & Very high & High & High \\
& $(9,10,10)$ & $(9,10,10)$ & $(7,9,10)$ & $(7,9,10)$ \\
$\mathrm{A}_{2}$ & High & Moderate & Moderate & High \\
& $(7,9,10)$ & $(3,5,7)$ & $(3,5,7)$ & $(7,9,10)$ \\
$\mathrm{A}_{3}$ & Low & Low & Moderate & Moderate \\
& $(0.05,1,3)$ & $(0.05,1,3)$ & $(3,5,7)$ & $(3,5,7)$ \\
$\mathrm{A}_{4}$ & Moderate & Moderate & Low & Low \\
& $(3,5,7)$ & $(3,5,7)$ & $(0.05,1,3)$ & $(0.05,1,3)$ \\
$\mathrm{A}_{5}$ & Low & Low & Very Low & Low \\
& $(0.05,1,3)$ & $(0.05,1,3)$ & $(.05,05,1)$ & $(0.05,1,3)$ \\
Importance (sub-group I) & Moderate & Moderate & High & Very high \\
& $(3,5,7)$ & $(3,5,7)$ & $(7,9,10)$ & $(9,10,10)$ \\
Importance (sub-group II) & High & Very high & Moderate & Moderate \\
& $(7,9,10)$ & $(9,10,10)$ & $(3,5,7)$ & $(3,5,7)$ \\
\hline
\end{tabular}
a. Congestion on hiking trails
b. Congestion on highway
c. Soil erosion along hiking trails
d. Vegetative losses along hiking trails

Table 5. Normalized fuzzy effects matrix for visitor use scenario $\mathrm{U}_{2}$, and sub-groups I and II, first time period

\begin{tabular}{lcccc}
\hline Manage. action & $\mathrm{CT}$ & $\mathrm{CH}$ & $\mathrm{SE}$ & $\mathrm{VL}$ \\
\hline $\mathrm{A}_{1}$ & $(.005, .005, .00556)$ & $(.005, .0056, .0056)$ & $(.00556, .00625, .00714)$ & $(.00556, .00625, .00714)$ \\
$\mathrm{A}_{2}$ & $(.00556, .00625, .00714)$ & $(.00714, .01, .01667)$ & $(.00714, .01, .01667)$ & $(.00556, .00625, .00714)$ \\
$\mathrm{A}_{3}$ & $(.01667, .05, .01667)$ & $(.01667, .05,1)$ & $(.00714, .01, .01667)$ & $(.00714, .01, .01667)$ \\
$\mathrm{A}_{4}$ & $(.00714, .01, .01667)$ & $(.00714, .01, .01667)$ & $(.01667, .05,1)$ & $(.01667, .05,1)$ \\
$\mathrm{A}_{5}$ & $(.01667, .05,1)$ & $(.01667, .05,1)$ & $(.05,1,1)$ & $(.01667, .05,1)$ \\
\hline
\end{tabular}


Table 6. Weighted normalized fuzzy effects matrices for sub-groups I and II under visitor use scenario $\mathrm{U}_{2}$ in the first time period

\begin{tabular}{lcccc}
\hline & \multicolumn{4}{c}{ Sub-group I } \\
\cline { 2 - 5 } Manage. action & $\mathrm{CT}$ & $\mathrm{CH}$ & $\mathrm{SE}$ & $\mathrm{VL}$ \\
\hline $\mathrm{n}_{1}$ & $(.0015, .0025, .00389)$ & $(.0015, .0025, .00389)$ & $(.00389, .00563, .00714)$ & $(.005, .00625, .00614)$ \\
$\mathrm{A}_{2}$ & $(.00167, .00313, .005)$ & $(.00214, .005, .00117)$ & $(.005, .009, .01667)$ & $(.005, .00625, .00614)$ \\
$\mathrm{A}_{3}$ & $(.005, .025, .7)$ & $(.005, .025, .7)$ & $(.005, .009, .016670$ & $(.00643, .01, .01667)$ \\
$\mathrm{A}_{4}$ & $(.00214, .005, .01167)$ & $(.00214, .005, .01167)$ & $(.01167, .045,1)$ & $(.015, .05,1)$ \\
$\mathrm{A}_{5}$ & $(.005, .025, .7)$ & $(.005, .025, .7)$ & $(.035, .9,1)$ & $(.015, .05,1)$ \\
\cline { 2 - 5 } & $(.0035, .0045, .00556)$ & $(.0045, .005, .00556)$ & $(.00167, .00313, .005)$ & $(.00167, .00313, .005)$ \\
$\mathrm{A}_{1}$ & $(.00389, .00563, .00714)$ & $(.00643, .01, .0167)$ & $(.00214, .005, .01167)$ & $(.00167, .00313, .005)$ \\
$\mathrm{A}_{2}$ & $(.01167, .045,1)$ & $(.015, .05,1)$ & $(.00214, .005, .01167)$ & $(.00214, .005, .01167)$ \\
$\mathrm{A}_{3}$ & $(.005, .009, .01667)$ & $(.00643, .05, .01667)$ & $(.005, .025, .7)$ & $(.005, .025, .7)$ \\
$\mathrm{A}_{4}$ & $(.01167, .045,1)$ & $(.015, .05,1)$ & $(.015, .5, .7)$ & $(.005, .025, .7)$ \\
$\mathrm{A}_{5}$ & & & Sub-group II & \\
\hline
\end{tabular}

Table 7. Distances of management actions from the positive- and negative-ideal solutions, vertex distances, closeness coefficients, and ranks of management actions for sub-groups I and II under $\mathrm{U}_{2}$ in the first time period

\begin{tabular}{|c|c|c|c|c|c|c|c|c|c|c|c|c|}
\hline \multirow{2}{*}{$\begin{array}{l}\text { Mange. } \\
\text { action }\end{array}$} & \multicolumn{8}{|c|}{ Distances from positive and negative ideal solutions } & \multicolumn{2}{|c|}{ Vertex distances } & \multirow{2}{*}{$\frac{\text { Closeness }}{\text { coefficient }}$} & \multirow[t]{2}{*}{ Rank } \\
\hline & $\mathrm{dVL}^{+}$ & $\mathrm{dVL}^{-}$ & $\mathrm{dCT}^{+}$ & $\mathrm{dCT}^{-}$ & $\mathrm{dCH}^{+}$ & $\mathrm{dCH}^{-}$ & $\mathrm{dSE}^{+}$ & $\mathrm{dSE}^{-}$ & $\mathrm{di}^{+}$ & $\mathrm{di}^{-}$ & & \\
\hline & \multicolumn{12}{|c|}{ Sub-group I } \\
\hline $\mathrm{A}_{1}$ & 0.989 & 0.006 & 0.003 & 0.992 & 0.003 & 0.992 & 0.006 & 0.989 & 1.000 & 2.980 & 0.251 & 5 \\
\hline $\mathrm{A}_{2}$ & 0.989 & 0.006 & 0.004 & 0.992 & 0.007 & 0.989 & 0.011 & 0.985 & 1.011 & 2.971 & 0.254 & 4 \\
\hline $\mathrm{A}_{3}$ & 0.984 & 0.012 & 0.402 & 0.819 & 0.402 & 0.819 & 0.011 & 0.985 & 1.800 & 2.634 & 0.406 & 2 \\
\hline $\mathrm{A}_{4}$ & 0.786 & 0.575 & 0.007 & 0.989 & 0.007 & 0.989 & 0.575 & 0.790 & 1.376 & 3.342 & 0.292 & 3 \\
\hline \multirow[t]{2}{*}{$\mathrm{A}_{5}$} & 0.786 & 0.575 & 0.402 & 0.819 & 0.402 & 0.819 & 0.773 & 0.557 & 2.364 & 2.770 & 0.460 & 1 \\
\hline & \multicolumn{12}{|c|}{ Sub-group II } \\
\hline $\mathrm{A}_{1}$ & 0.992 & 0.004 & 0.005 & 0.990 & 0.005 & 0.990 & 0.004 & 0.992 & 1.005 & 2.976 & 0.252 & 5 \\
\hline $\mathrm{A}_{2}$ & 0.992 & 0.004 & 0.006 & 0.989 & 0.012 & 0.984 & 0.007 & 0.989 & 1.017 & 2.966 & 0.255 & 4 \\
\hline $\mathrm{A}_{3}$ & 0.989 & 0.007 & 0.575 & 0.790 & 0.575 & 0.786 & 0.007 & 0.989 & 2.146 & 2.572 & 0.455 & 2 \\
\hline $\mathrm{A}_{4}$ & 0.819 & 0.402 & 0.011 & 0.985 & 0.012 & 0.984 & 0.402 & 0.819 & 1.244 & 3.190 & 0.281 & 3 \\
\hline $\mathrm{A}_{5}$ & 0.819 & 0.402 & 0.575 & 0.790 & 0.575 & 0.786 & 0.494 & 0.658 & 2.463 & 2.636 & 0.483 & 1 \\
\hline
\end{tabular}

\subsection{Determining Preferred Management Actions for Time Periods}

The preferred management action across visitor use scenarios for each time period based on the minimax regret criterion is the one that minimizes a maximum loss index (MLI) over the preferred management actions for $\mathrm{U}_{1}, \mathrm{U}_{2}$, and $\mathrm{U}_{3}$. The MLI for the preferred management action for a visitor use scenario is a weighted average of the expected maximum losses in the four objectives when that management action is used. Expected maximum loss for a single objective with the preferred management action for a visitor use scenario is the estimated value of that objective with that action when there is no future growth in visitor use in the corridor minus the estimated value of that objective with that action and the visitor use scenario for which that action is preferred. Losses in individual objectives without and with future growth in visitor use are estimated using expert judgment, surveys, and/or simulation models. Construction of the MLI requires the group to assign weights to the four management objectives, such that the weights sum to one. 
The application of the minimax regret criterion for the first time period is illustrated in Table 8. Because $\mathrm{A}_{4}$ minimizes the value of the maximum loss index, it is the preferred management action in the first time period. Preferred management actions for the second through fourth time periods are determined in a similar manner.

Table 8. Values of maximum loss indices for preferred management actions for three visitor use scenarios, first time period

\begin{tabular}{lccc}
\hline Visitor use scenario & $\mathrm{U}_{1}$ & $\mathrm{U}_{2}$ & $\mathrm{U}_{3}$ \\
Preferred management action & $\mathrm{A}_{4}$ & $\mathrm{~A}_{5}$ & $\mathrm{~A}_{5}$ \\
Maximum loss index & 45 & 58 & 65 \\
\hline
\end{tabular}

\section{Discussion}

This section provides additional details regarding the selection of the parameters listed in Table 2.

Time periods (parameter 1) should be long enough to allow enough time for any changes in management actions implemented at the beginning of a time period to fully influence the management objectives by the end of that time period. The more slowly the management objectives are likely to respond to changes in management actions, the longer the time periods need to be. Planning requirements for national park units are likely to influence the length of the planning period as well as the other planning parameters listed in Table 2. For example, development of general management plans for U.S. national park units must be in compliance with the 1978 National Parks and Recreation Act, and agency guidelines provided by the Park Planning and Special Studies Division in the national office (National Park Service undated (b)).

The number of management actions (parameter 2) should be sufficiently large to encompass a range of possibilities for resolving the problem framed by the group. The types of the management actions (parameter 2) depend on the nature of the problem which those actions are intended to address. Management actions adopted by other CHANS facing similar management problems could prove useful in developing management actions for the CHANS under consideration. Management actions need to be sufficiently different from one another.

An earlier discussion explained that management objectives selected by the group (parameter 3) must be supportive of the mission of the agency managing the CHANS. The scenarios for future visitor use of the corridor (parameter 4) should encompass a wide range of possible visitor use levels and the scenarios themselves should be significantly different from one another.

Values of the management objectives for each management action (parameter 5) are estimated using monitoring data, expert judgment, surveys, and/or simulation models. Application of these methods is probably the most difficult task facing the group. Narrative rating of the objectives and importance of the objectives (parameter 6) is subjective and can be facilitated using an assignment algorithm as mentioned earlier.

To the extent possible, the group should select maximum acceptable levels of the objectives (parameter 7) based on established standards for the objectives, if they exist. Selection of the reliability levels for compliance (parameter 8) is subjective.

Application of fuzzy TOPSIS (parameter 9) requires the group to narratively rate the estimated values of objectives for each management action, visitor use scenario, and time period and the importance of the objectives, assign fuzzy numbers to the narrative ratings, and perform several mathematical operations. If a large number of narrative ratings are required, it is advantageous to develop an assignment algorithm for this purpose.

The mathematical operations required to generate Tables 5 through 7 can be performed using a spreadsheet developed by the author. The spreadsheet requires the user to select numerical codes for the five narrative ratings (e.g., 1 for very low, 2 for low, 3 for moderate, 4 for high, and 5 for very high) and assign a code to the estimated values of every objective for all $(\mathrm{A}-\mathrm{U})_{\mathrm{i}} \mathrm{s}$ and time periods and the importance of the objectives. Based on this information, the spreadsheet automatically generates Tables 5 through 7 .

Application of the minimax regret criterion (parameter 9) is relatively straightforward once the MLIs have been calculated. Calculating MLIs requires a group to estimate the values of the objectives for each management action and time period when there is no future visitor growth and for each $(\mathrm{A}-\mathrm{U})_{\mathrm{i}}$, and select weights for the objectives. Both tasks can be accomplished using simulation techniques and/or the Delphi method. 
Agreement on the parameters listed in Table 2 can occur two ways. First, if there is minor disagreement among group members about the values of a specific parameter, then an average value can be used for that parameter. In particular, average parameter values can be used when members of the group have slightly different maximum acceptable levels of objectives, reliability levels for compliance with maximum acceptable levels of objectives, narrative ratings for the estimated values of the objectives and their importance and corresponding triangular fuzzy numbers for those ratings, algorithms for assigning narrative ratings to estimated values of objectives, estimated values of the objectives without future growth in visitation, and weights for objectives in the MLIs.

Second, if there are major disagreements among group members about the values of a particular parameter, then management actions should be evaluated and ranked using different sets of values for those parameters. This approach was demonstrated in section 3.3 where two different narrative ratings of the importance of the objectives were used to rank management actions.

\section{Conclusions}

The conceptual framework described here is general enough to be used by CDM groups to determine preferred management actions over time for a CHANS when there is uncertainty about future changes in one or more drivers of the outcomes of management actions. Major analytical methods employed in the framework include: (1) using probabilistic decision rules to determine compliance of management actions with maximum or minimum acceptable values of the objectives; (2) employing fuzzy TOPSIS to determine the preferred management action for each driver scenario within time periods; and (3) applying the minimax regret criterion to identify the preferred management action across driver scenarios within time periods. The hypothetical case study demonstrates how to apply the conceptual framework when there is uncertainty about future visitor use in the corridor. However, the same framework can be used to account for uncertainty about other major drivers of system behavior, such as climate change and variability.

Many fuzzy logic-based decision rules require the use of complex mathematical operations. In contrast, the fuzzylogic elements of the conceptual framework described here are easier for a group to apply. However, certain elements of the framework, notably using expert judgment, surveys, and/or simulation models to estimate the values of management objectives, are more challenging to apply and would most likely require the group to enlist the assistance of individuals familiar with the application of those methods.

Application of the framework will likely give rise to disagreements among group members regarding one or more parameters of the framework. If disagreements pertaining to the first parameter set cannot be resolved before applying the methods, then use of the framework may be invalidated. In contrast, disagreements pertaining to the second parameter set can be handled by having a group reach agreement on the parameters before applying the framework or, if that is not possible, ranking management actions using parameter values selected by different members of the group.

\section{Acknowledgements}

The research reported here was supported in part by the National Science Foundation, Award ID 0903562.

\section{References}

Ansell, C., \& Gash, A. (2008). Collaborative governance in theory and practice. Journal of Public Administration Research and Theory, 18, 543-571. http://dx.doi.org/10.1093/jopart/mum032

Brown, G., \& Harris, C. C. (2000). The US Forest Service: Whither the new resource management paradigm? Journal of Environmental Management, 58, 1-19. http://dx.doi.org/10.1006/jema.1999.0310

Brunner, R. D., Steelman, T. A., Coe-Juell, L., Cromley, C. M., Edwards, C. M., \& Tucker, D. W. (2005). Adaptive governance, integrating science, policy and decision making. New York, NY: Columbia University Press.

Chen, C.-T. (2000). Extensions to the TOPSIS for group decision-making under fuzzy environment. Fuzzy Sets and Systems, 114, 1-9. http://dx.doi.org/10.1016/S0165-0114(97)00377-1

Chen, S. J., \& Hwang, C. L. (1992). Fuzzy multiple attribute decision making. Lecture notes in economics and mathematical systems, No. 375. Berlin: Springer-Verlag. http://dx.doi.org/10.1007/978-3-642-46768-4

Cherney, D. N., \& Clark, S. G. (2009). The American West's longest large mammal migration: clarifying and securing the common interest. Policy Sciences, 42, 95-111. http://dx.doi.org/10.1007/s11077-008-9059-x

Cole, D. N., \& Bayfield, N. G. (1993). Recreational trampling of vegetation: standard experimental procedures. Biological Conservation, 63, 209-215. http://dx.doi.org/10.1016/0006-3207(93)90714-C 
Gunton, T. I., \& Day, J. C. (2003). The theory and practice of collaborative planning in resource and environmental management. Environments, 3, 5-19.

Herath, G., \& Prato, T. (Eds.). (2006). Using multi-criteria decision analysis in natural resource management: Empirical applications. UK: Ashgate Publishing, Ltd.,.

Hill, R., \& Pickering, C. M. (2009). Differences in the resistance of three subtropical vegetation types to experimental trampling. Journal of Environmental Management, 90, 305-1312. http://dx.doi.org/10.1016/j.jenvman.2008.07.015

Holling, C. S. (1978). Adaptive Environmental Assessment and Management. Wiley: Chichester, England.

Johnson, T. R. (1999). Community-based forest management in the Philippines. Journal of Forestry, 97, 26-30.

Linstone, H. A., \& Turoff, M. (eds.) (2002). The Delphi Method: Techniques and Applications. Retrieved November 30, 2015 from http://is.njit.edu/pubs/delphibook/

Liu, J., Dietz, T., Carpenter, S. R., Alberti, M., Folke, C., Moran, ... Taylor, W. W. (2007). Complexity of coupled human and natural systems. Science, 317, 1513-1516. http://dx.doi.org/10.1126/science.1144004

Long, R. J., \& Beierle, T. C. (1999). The Federal Advisory Committee Act and public participation in environmental policy. Discussion Paper 99-17. Washington, DC: Resources for the Future,

Lybecker, D., Lamb, B. L., \& Ponds, P. D. (2002). Public attitudes and knowledge of the black-tailed prairie dog: A common and controversial species. BioScience, 52, 607-613. http://dx.doi.org/10.1641/0006-3568(20 02)052[0607:PAAKOT]2.0.CO;2

Management Plans. (n.d.). In National Park Service, PEPC Planning, Environment \& Public Comment. Management Plans. Retrieved November 30, 2015, from http://parkplanning.nps.gov/ManagementPlans. $\mathrm{cfm}$.

McDonald, B. (2001). Book review of Wondolleck, J. M., \& Yaffee, S. L. (2000). Making collaboration work: Lessons from innovation in natural resources management. Washington, DC: Island Press, Pp. 277. Natural Resources Journal, 41, 1033-1035.

McLaughlin, G., Primm, S., \& Rutherford, M. B. (2005). Participatory projects for coexistence: rebuilding civil society. In T. W. Clark, M. B. Rutherford, \& D. Casey (Eds.), Coexisting with large carnivores: lessons from Greater Yellowstone (pp. 177-210). Washington, DC: Island Press.

Olive, N. D., \& Marion, J. L. (2009). The influence of use-related, environmental, and managerial factors on soil loss from recreational trails. Journal of Environmental Management, 90, 1483-1493. http://dx.doi.org/10.10 16/j.jenvman.2008.10.004

Parma, A.M. (1998). NCEAS Working Group on Population Management. What can adaptive management do for our fish, forest, food, and biodiversity? Integrative Biology, 1, 16-26. http://dx.doi.org/10.1002/(SICI)1 520-6602(1998)1:1<16::AID-INBI3>3.0.CO;2-D

Pelletier, D., Kraak, V., McCullum, C., Uusitalo, U., \& Rich, R. (1999). The shaping of collective values through deliberative democracy: an empirical study from New York's North Country. Policy Sciences, 32, 103-131. http://dx.doi.org/10.1023/A:1004641300366

Peterson, M. N., Peterson, M. J., \& Peterson, T. R. (2005). Conservation and the myth of consensus. Conservation Biology, 19, 762-767. http://dx.doi.org/10.1111/j.1523-1739.2005.00518.x

Pickering, C. M., Hill, W., Newsome, D., \& Leung Y. F. (2010). Comparing hiking, mountain biking and horse riding impacts on vegetation and soils in Australia and the United States of America. Journal of Environmental Management, 91, 551-562. http://dx.doi.org/10.1016/j.jenvman.2009.09.025

Prato, T. (2009). Fuzzy adaptive management of social and ecological carrying capacities for protected areas. Journal of Environmental Management, 90, 2551-2557. http://dx.doi.org/10.1016/j.jenvman.2009.01.015

Prato, T. (2012). Increasing resilience of natural protected areas to future climate change: A fuzzy adaptive management approach. Ecological Modelling, 242, 46-53. http://dx.doi.org/10.1016/j.ecolmodel.2012.0 5.014

Prato, T., \& T. Paveglio. (2014). An integrated conceptual framework for adapting forest management practices to alternative futures. International Journal of Forestry Research, 2014. http://dx.doi.org/10.1155/2014/ 321345. 
Prato, T., Qiu, Z., Pederson, G., Fagre, D., Bengtson, L., \& Williams, J. (2010). Potential economic benefits of adapting agricultural production systems to future climate change. Environmental Management, 45, 577-589. http://dx.doi.org/10.1007/s00267-010-9427-0.

Richardson, J. W., Schumann, K. D., \& Feldman, P. A. (2008). Simetar: simulation and econometrics to analyze risk. TX: College Station. http://simetar.com/Portals/18/Simetar\%202011\%20Users\%20Manual.pdf

Rutherford, M. B., Gibeau, M. L., Clark, S. G., \& Chamberlain, E. C. (2009). Interdisciplinary problem solving workshops for grizzly bear conservation in Banff National Park, Canada. Policy Sciences, 42, 163-187. http://dx.doi.org/10.1007/s11077-009-9075-5

Smith, P. D., McDonough, M. H., \& Mang, M. T. (1999). Ecosystem management and public participation: Lessons from the field. Journal of Forestry, 97, 32-38.

Steinitz, C. H., Flaxman, M., Mouat, D., Arias, H., Goode, T., Peiser, R., ..., \& Shearer, A. (2003). Alternative futures for changing landscapes: The Upper San Pedro River Basin in Arizona and Sonora. Washington, DC: Island Press.

Walters, C. (1986). Adaptive management of renewable resources. Caldwell, NJ: Blackburn Press.

Warner, J. (2015). Collaborative decision making. ReadyToManage. Retrieved September 29, 2015 from http://blog.readytomanage.com/collaborative-decision-making/.

Weinburg, S., \& Brandon, M. (1999). Facilitating collaborative decision-making in six steps. International Association of Facilitators 1999 Annual Meeting, Williamsburg, VA, January 14-17. USA. Retrieved November 30, 2015 from http://www.amauta-international.com/iaf99/Thread4/weinberg.html.

Welcome to Park Planning. (n.d.b). In National Park Service, PEPC Planning, Environment \& Public Comment. Management Plans. Retrieved November 30, 2015, from http://parkplanning.nps.gov/planningHome.cfm.

Wondolleck, J. M., \& Yaffee, S. L. (2000). Making collaboration work: Lessons from innovation in natural resources management. Washington, DC: Island Press

\section{Copyrights}

Copyright for this article is retained by the author(s), with first publication rights granted to the journal.

This is an open-access article distributed under the terms and conditions of the Creative Commons Attribution license (http://creativecommons.org/licenses/by/3.0/). 